\title{
Air-Curable, High-Resolution Patternable Oxetane-Based Liquid Crystalline Photonic Films via Flexographic Printing
}

\author{
Davey C. Hoekstra, ${ }^{\dagger}$ Koen Nickmans, ${ }^{\ddagger}$ Johan Lub, ${ }^{\dagger}$ Michael G. Debije, ${ }^{\dagger \oplus}$
} and Albert P. H. J. Schenning, $*,, \S, \| \odot$

\begin{abstract}
${ }^{\dagger}$ Stimuli-Responsive Functional Materials and Devices, Department of Chemical Engineering and Chemistry, Eindhoven University of Technology, P.O. Box 513, 5600 MB Eindhoven, The Netherlands

${ }^{\ddagger}$ FreshStripsFnB BV, High Tech Campus 1, 5656 AE Eindhoven, The Netherlands

${ }^{\S}$ Institute for Complex Molecular Systems, Eindhoven University of Technology, Den Dolech 2, 5600 MB Eindhoven, The Netherlands

"SCNU-TUE Joint Laboratory of Device Integrated Responsive Materials (DIRM), South China Normal University, Guangzhou Higher Education Mega Center, 510006 Guangzhou, China
\end{abstract}

Supporting Information

ABSTRACT: The production of patterned photonic films on a large scale remains a challenge. Here, we report on a new class of photonic materials that are based on oxetane liquid crystals (LCs). Patterned reflective coatings can be produced from these materials on flexible substrates by using flexographic printing. This industrially relevant process allows for upscaling in future applications. Furthermore, the oxetane LCs used do not require an inert atmosphere for photopolymerization, unlike previously described acrylate systems. We show that the flexographic printing process results in excellent alignment, and that the patterns produced display a high resolution. Additionally, we demonstrate that free-standing photonic reflecting foils can also be produced from these materials. Our new oxetane-based patterned iridescent colored materials have potential application for both esthetic purposes as well as anticounterfeit labels.

KEYWORDS: liquid crystals, flexographic printing, oxetane polymers, photonic crystals, reflective films

\section{INTRODUCTION}

Many examples of iridescent objects which change color as the angle of viewing changes can be found in nature. Often, this iridescent appearance arises from the inner nanostructure of the materials. This phenomenon is often referred to as structural coloration. Examples of iridescent structural colors in organisms include the wings of Morpho butterflies, ${ }^{1}$ the leaves of the Hibiscus trionum flower, ${ }^{2}$ and the exoskeleton of the Tmesisternus isabellae beetle. ${ }^{3}$ Structural color allows organisms to selectively reflect specific wavelengths of light for purposes such as camouflage or deterring predators. ${ }^{4}$

Inspired by these examples, researchers have mimicked these iridescent structural colors using one-dimensional (1D) nanostructured photonic crystals. ${ }^{5}$ These artificial photonic materials have been used in a wide range of applications, including sensors, ${ }^{6-8}$ anticounterfeit labels, ${ }^{9-11}$ rewritable photonic papers, ${ }^{12-15}$ and for energy saving in the built environment. $^{16-18}$ Additionally, by photopatterning these photonic materials, one can generate additional attractive optical effects. ${ }^{19}$ These colorful photonic materials can be obtained using various techniques, such as inkjet printing, ${ }^{11,20}$ lithography, $^{21,22}$ or selective infiltration. ${ }^{23,24}$
A widely used class of materials for fabricating photonic structures are chiral nematic or cholesteric liquid crystals (ChLCs). ${ }^{25-27}$ Adding a chiral dopant to a nematic liquid crystalline (LC) phase induces a helical twist of the molecular director. ${ }^{25}$ This twist results in a periodic refractive index variation. Hence, the material resembles a $1 D$ photonic crystal that can selectively reflect light. ${ }^{25}$ Tuning the pitch of the helix (i.e., the length that is required for a full rotation of the molecular director) alters the wavelength of light that is reflected. $^{28}$

Despite these potential applications for Ch-LCs, there are still some challenges. Currently, the fabrication methods for Ch-LC-based materials are often complicated. They require the use of alignment in glass cells to obtain the correct LC orientation, for example. ${ }^{15,18,19,29}$ However, for future largescale production, a manufacturing procedure is required that is simple, easily scalable, and industrially relevant. Until now, only a few examples have been reported where Ch-LC coatings

Received: December 7, 2018

Accepted: January 28, 2019

Published: January 28, 2019 
(a)<smiles>[Z]C1COC1COCCCOc1ccc(C(=O)Oc2ccc(OC(=O)c3ccc(OCCCCCC)cc3)cc2C)cc1</smiles><smiles></smiles>

3

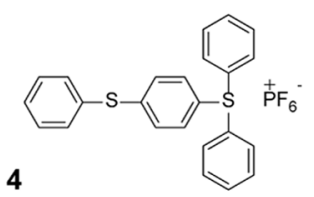

4

(b)

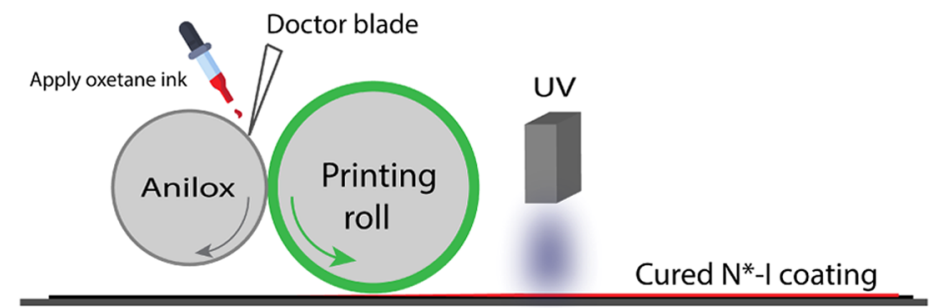

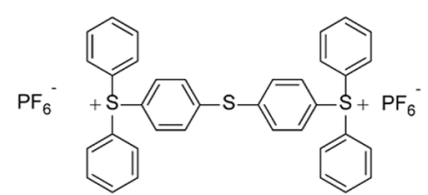

$+\mathrm{PF}_{6}$

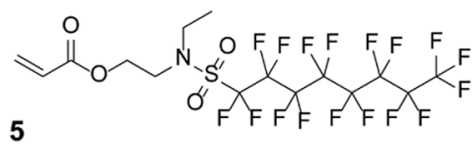

(c)

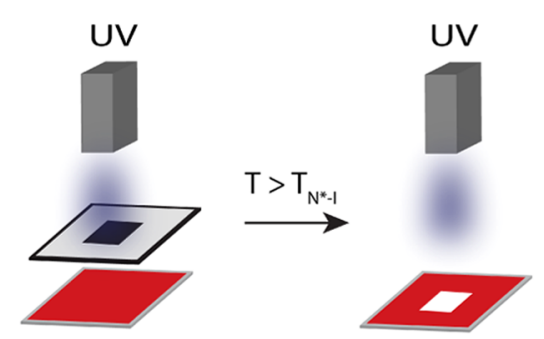

Figure 1. (a) Molecular structures of the chemicals used. (b) Schematic overview of flexographic printing process followed by curing in air. (c) Lithographic patterning of chiral nematic LC oxetane coatings. The red regions depict areas with chiral nematic alignment and white regions are areas polymerized in the isotropic state.

were prepared by simple techniques, such as inkjet printing or blade-coating. ${ }^{15,22,30,31}$ However, these coatings are normally still applied on glass substrates that were first covered with alignment layers. For future applications in sensors or anticounterfeit labels, for instance, it would be desirable to fabricate these materials on flexible (plastic) substrates. The first examples of Ch-LC coatings on plastic substrates have been recently reported, using techniques such as bar coating $^{29,32}$ and screen printing. ${ }^{33}$

Another challenge in the large-scale production of Ch-LC coatings are the photopolymerization conditions. To date, most Ch-LC systems that have been reported are based on reactive mesogens (RMs). ${ }^{19,34}$ These LC molecules consist of a mesogenic core with a polymerizable end group that is attached to this core via a flexible carbon spacer. ${ }^{35}$ These RMs provide a very versatile toolbox for the production of Ch-LC films or coatings. Most of these RMs use (meth)acrylates as the polymerizable group. ${ }^{19}$ The free-radical photopolymerization of these (meth)acrylates is very robust and widely used in industry. However, (meth)acrylates are also reported to suffer from polymerization shrinkage and oxygen inhibition, which can especially be a problem in the polymerization of thin films or coatings. ${ }^{36}$ A nitrogen atmosphere must then be used to achieve efficient polymerization, which is undesirable for largescale production. ${ }^{37}$

To avoid these drawbacks, other polymerizable groups can be used that polymerize through other mechanisms. For example, liquid crystalline vinyl ethers, ${ }^{38}$ epoxides, ${ }^{39}$ and oxetanes have already been reported in the literature. ${ }^{37,40}$ of these systems, oxetane-based RMs have been found to be the most promising alternatives for LC acrylates. Oxetanes have a faster rate of polymerization than epoxides and vinyl ethers. ${ }^{40}$ Furthermore, oxetanes do not suffer from side reactions, like epoxides do, ${ }^{41}$ and the ring-opening polymerization of an oxetane leads to less polymerization shrinkage than the corresponding acrylate $\mathrm{RM}^{40}$ Despite these advantages, oxetane-based RMs have so far only been used to fabricate patterned retarders for transflective liquid crystal displays (LCDs). ${ }^{37}$ Application of oxetanes in films or chiral nematic coatings has not been reported.

In this work, we have developed a new class of photonic materials based on a chiral nematic liquid crystalline oxetane mixture by synthesizing an oxetane-functionalized chiral dopant (Figure 1a). We have used these oxetane LCs to fabricate both chiral nematic free-standing foils as well as coatings using flexographic printing on a flexible substrate (Figure $1 \mathrm{~b}$ ). Not only is this method able to produce Ch-LC coatings on a relatively large scale and at high speed, it is also a preferred method for the large-scale reel-to-reel production of labels and packaging materials. Therefore, future upscaling of coating production should be relatively easy. Moreover, we have shown that these coatings can be patterned with a high resolution by making use of a simple photomask during photopolymerization.

\section{EXPERIMENTAL SECTION}

Characterization. NMR spectra were recorded on a $400 \mathrm{MHz}$ Bruker Avance III HD spectrometer with tetramethyl silane used as an internal standard. Matrix-assisted laser desorption/ionization time-offlight mass spectrometry (MALDI-TOF MS) was performed on a Bruker Autoflex Speed MALDI-MS instrument. Differential scanning calorimetry (DSC) curves were measured with a DSC Q2000 from TA Instruments. Fourier-transform infrared (FTIR) was measured on a Varian 670-IR FTIR spectrometer. UV-vis spectroscopy was performed on a Perkin Elmer Lambda 750 spectrometer equipped with a $150 \mathrm{~mm}$ integrating sphere, with a tungsten halogen light source for measurements between 320 and $850 \mathrm{~nm}$. For transmission 


\section{Scheme 1. Synthetic Route towards Oxetane-Functionalized Chiral Dopant 3}

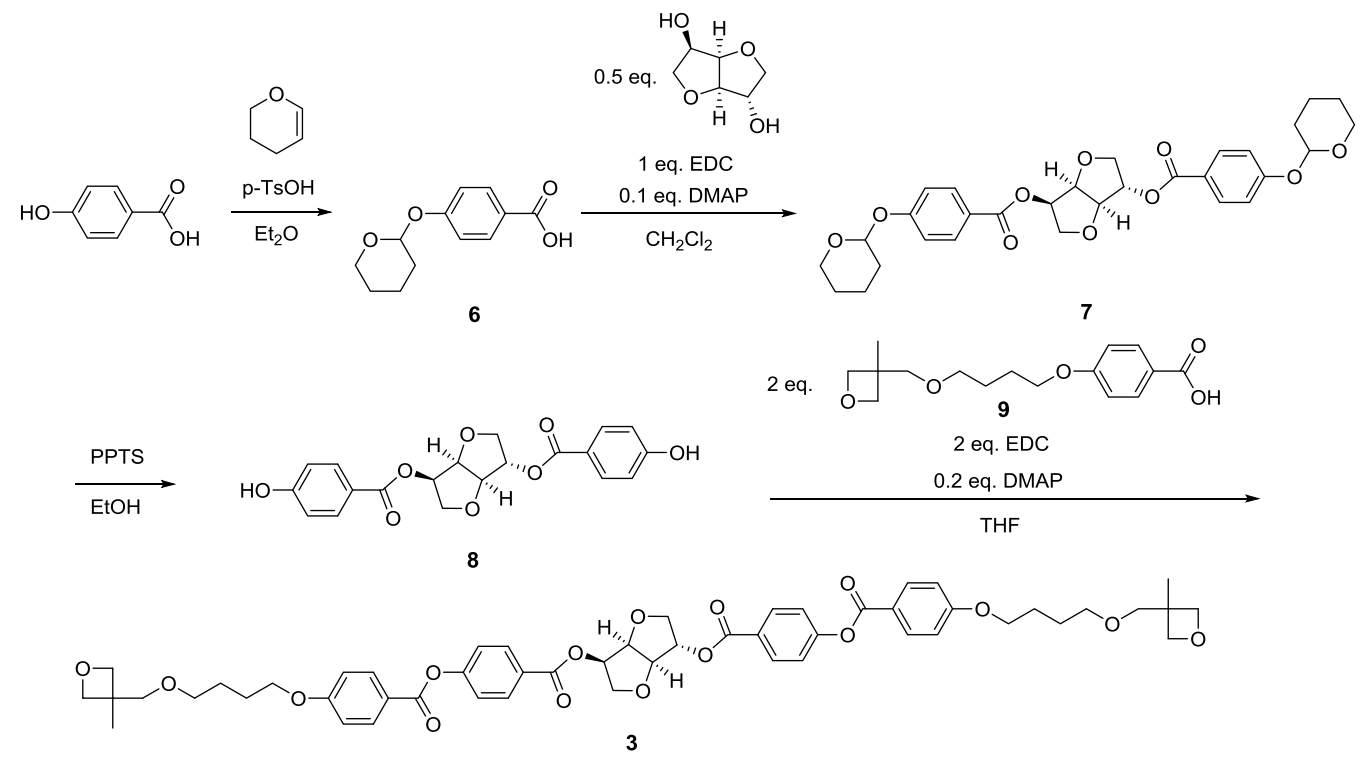

measurements, the sample was placed in front of the inlet port of the integrating sphere at normal incidence with respect to the sample beam and for reflection measurements, the sample was placed at the back of the outlet port of the integrating sphere at a small angle of incidence $\left(7^{\circ}\right)$. Both measurements used air as a reference. Pictures of samples were taken with an Olympus OM-D E-M10III camera equipped with an Olympus MFT 60 MM F/2.8 ED Macro M.Zuiko Digital lens. Micrograph images were recorded on a Leica CTR6000 polarized optical microscope equipped with a Leica DFC $420 \mathrm{C}$ camera. Dynamic mechanical thermal analysis (DMTA) was performed with a DMA Q800 apparatus (TA Instruments) on $10 \times$ $5.3 \mathrm{~mm}^{2}$ ribbons cut from the larger Ch-LC foils. Elastic moduli and damping characteristics $(\tan \delta$-value) were measured at a $1 \mathrm{~Hz}$ frequency and a $30 \mu \mathrm{m}$ amplitude.

Materials. 2-Methyl-1,4-phenylene bis(4-(4-((3-methyloxetan-3yl)methoxy)butoxy)benzoate) (1), 4-((4-(hexyloxy)benzoyl)oxy)-2methylphenyl 4-(4-((3-methyloxetan-3-yl)methoxy)butoxy)benzoate (2), and 4-(4-((3-methyloxetan-3-yl)methoxy)butoxy)benzoic acid (9) were obtained from Philips Research. The cationic photoinitiator, triarylsulfonium hexafluorophosphate salts in propylene carbonate (4), was purchased from Sigma-Aldrich. The surfactant, 2-[N-Ethyl$\mathrm{N}$-(perfluorooctylsulfonyl)amino] ethyl acrylate (5), was purchased from Acros. All solvents were purchased from Biosolve.

Synthesis. Synthetic details of $\mathbf{6 , 7}$, and $\mathbf{8}$ are given in the Supporting Information.

Synthesis of $(3 R, 3 \mathrm{a} R, 6 S, 6 \mathrm{a} R)$-hexahydrofuro[3,2-b] furan-3,6-diyl bis(4-((4-(4-((3-methyloxetan-3-yl)methoxy)butoxy)benzoyl)oxy)benzoate) (3).

To a solution of $1.37 \mathrm{~g}(4.66 \mathrm{mmol})$ of 4-(4-((3-methyloxetan-3yl)methoxy)butoxy)benzoic acid (3), $0.90 \mathrm{~g}$ (2.33 mmol) of $(3 R, 3 a R, 6 S, 6 a R)$-hexahydrofuro[3,2-b]furan-3,6-diyl bis(4-hydroxybenzoate) (8), and $121.9 \mathrm{mg}(0.98 \mathrm{mmol})$ of 4-dimethylamino pyridine (DMAP) in $100 \mathrm{~mL}$ of THF cooled to $0{ }^{\circ} \mathrm{C}$ under argon was added $0.932 \mathrm{~g}(4.86 \mathrm{mmol})$ of $\mathrm{EDC} \cdot \mathrm{HCl}$ all at once. After stirring overnight at RT, the solvent was removed under reduced pressure. The resulting yellow oil was dissolved in $75 \mathrm{~mL}$ of dichloromethane (DCM) and extracted subsequently with $50 \mathrm{~mL}$ of a saturated $\mathrm{NaHCO}_{3}$ solution, $50 \mathrm{~mL}$ of water, and $50 \mathrm{~mL}$ of brine. After drying over anhydrous $\mathrm{MgSO}_{4}$, the solvent was removed under reduced pressure. The crude product was then purified by column chromatography on neutral alumina, eluting with $10 \%$ ethyl acetate in DCM. The resulting white solid was recrystallized from ethanol to give $0.85 \mathrm{~g}(39 \%)$ of pure 3 as white crystals.

${ }^{1} \mathrm{H}$ NMR $\left(400 \mathrm{MHz}, \mathrm{CDCl}_{3}\right): \delta 8.20-8.07(\mathrm{~m}, 8 \mathrm{H}), 7.35-7.27$ (m, 4H), 7.02-6.95 (m, 4H), $5.51(\mathrm{~d}, J=2.3 \mathrm{~Hz}, 1 \mathrm{H}), 5.44(\mathrm{q}, J=$
$5.4 \mathrm{~Hz}, 1 \mathrm{H}), 5.08(\mathrm{t}, J=5.1 \mathrm{~Hz}, 1 \mathrm{H}), 4.70(\mathrm{~d}, J=4.6 \mathrm{~Hz}, 1 \mathrm{H}), 4.52$ $(\mathrm{d}, J=5.7 \mathrm{~Hz}, 4 \mathrm{H}), 4.36(\mathrm{~d}, J=5.7 \mathrm{~Hz}, 4 \mathrm{H}), 4.16-4.03(\mathrm{~m}, 8 \mathrm{H})$, $3.56(\mathrm{t}, J=6.1 \mathrm{~Hz}, 4 \mathrm{H}), 3.50(\mathrm{~s}, 4 \mathrm{H}), 1.98-1.89(\mathrm{~m}, 4 \mathrm{H}), 1.84-1.76$ $(\mathrm{m}, 4 \mathrm{H}), 1.32(\mathrm{~s}, 6 \mathrm{H})$.

${ }^{13} \mathrm{C}$ NMR (101 MHz, $\left.\mathrm{CDCl}_{3}\right): \delta 165.23,164.89,164.32,164.28$, $163.67,155.19,155.13,132.42,131.40,131.38,126.88,126.83$, $121.99,121.11,121.07,114.39,86.21,81.17,80.16,78.54,77.36$, 76.15, 74.62, 73.51, 71.04, 70.79, 68.08, 39.93, 26.18, 26.09, 21.41.

HRMS (MALDI-TOF): $[\mathrm{M}+\mathrm{H}]^{+}$calcd for $\mathrm{C}_{52} \mathrm{H}_{58} \mathrm{O}_{16}$ : 939.37; found, $[\mathrm{M}+\mathrm{Na}]^{+}:$961.37.

Preparation of Free-Standing Foils. LC monomer mixtures were prepared consisting of $75 \%(\mathrm{w} / \mathrm{w})$ of oxetane crosslinker $(1+3)$ and $25 \%$ of 2 . These mixtures were dissolved in THF (1:1 solids/ solvent ratio) and $5 \%(\mathrm{w} / \mathrm{w}$, with respect to solids) of cationic photoinitiator 4 was added. The resulting solutions were filtered through a $0.22 \mu \mathrm{m}$ polytetrafluoroethylene (PTFE) syringe filter. Free-standing foils were prepared by depositing $100 \mu \mathrm{L}$ of monomer mixture on a glass slide. The slide was heated to $85{ }^{\circ} \mathrm{C}$ for $30 \mathrm{~min}$ to evaporate the solvent. Then, a second glass slide was placed on top and the mixture was allowed to spread throughout the entire cell. The cell was then slowly cooled to $55{ }^{\circ} \mathrm{C}$ (the chiral nematic phase). The monomer mixture was aligned by shearing the glass plates and then the material was photopolymerized for $10 \mathrm{~min}$ by exposure to light from an Omnicure EXFO2000 UV lamp at an intensity of $7 \mathrm{~mW} / \mathrm{cm}^{2}$. After polymerization, the cells were carefully opened using a razor and the chiral nematic foils were carefully removed from the substrate.

For lithographically patterned foils, the cell was polymerized using an Omnicure EXFO2000 UV source at $7 \mathrm{~mW} / \mathrm{cm}^{2}$ through a photomask for $30 \mathrm{~s}$. The sample was then heated to $85{ }^{\circ} \mathrm{C}$ (above the isotropic transition) and polymerized at full intensity $\left(30 \mathrm{~mW} / \mathrm{cm}^{2}\right)$ for $10 \mathrm{~min}$.

Preparation of Coatings. LC oxetane inks were prepared that consisted of $74.5 \%(\mathrm{w} / \mathrm{w})$ of oxetane crosslinker $(1+3), 25 \%$ of 2 , and $0.5 \%$ of surfactant $\mathbf{5}$. These mixtures were dissolved in cyclopentanone ( $1: 1$ solids/solvent ratio), to which $5 \%(\mathrm{w} / \mathrm{w}$, with respect to solids) cationic photoinitiator 4 was added. The resulting solutions were filtered through a $0.22 \mu \mathrm{m}$ PTFE syringe filter. Coatings were prepared on an IGT F1 printability tester in a "flexo" mode. Biaxially oriented PET (Tenolan OCN0003, $36 \mu \mathrm{m}$ thickness) was used as the substrate. After coating, the substrates were heated at $50{ }^{\circ} \mathrm{C}$ for $3 \mathrm{~min}$ to evaporate the solvent and align the CLC phase. Photopolymerization was then achieved by passing the substrate through an IGT UV Dryer in air to obtain the cured coating (intensity: $155 \mathrm{~mW} / \mathrm{cm}^{2}$ (UVA); $134 \mathrm{~mW} / \mathrm{cm}^{2}$ (UVB), dose: $88 \mathrm{~mJ} /$ $\mathrm{cm}^{2}$ (UVA); $73 \mathrm{~mJ} / \mathrm{cm}^{2}$ (UVB)). For lithographically patterned 
(a)

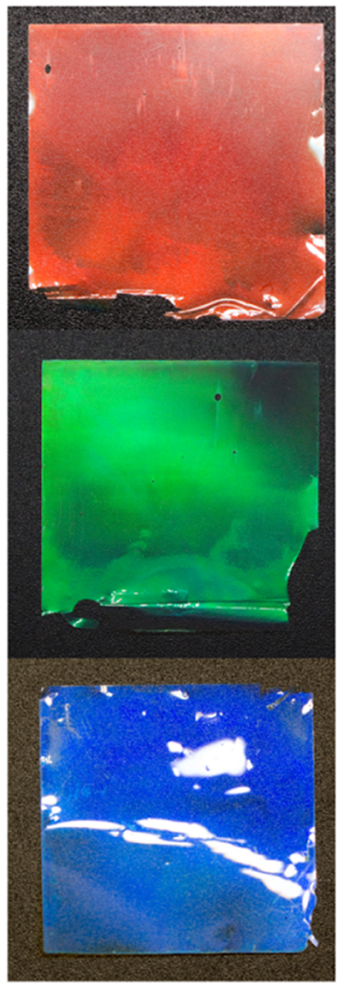

(b)

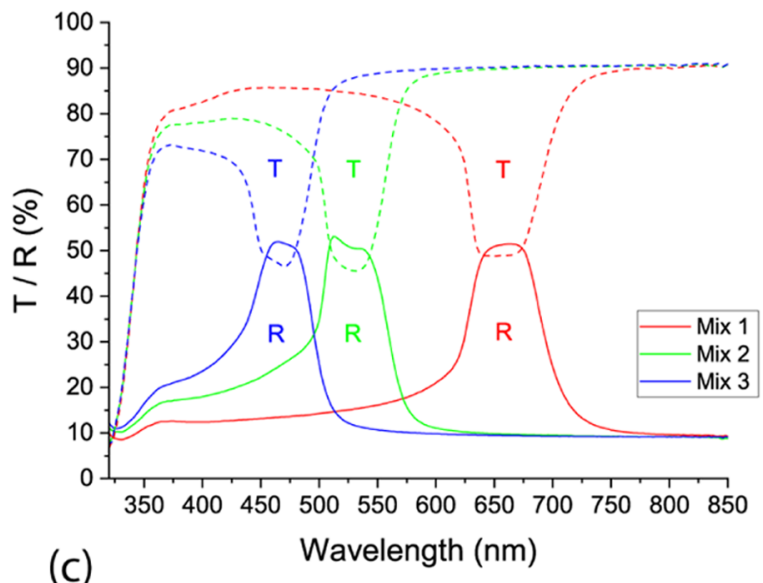

(c)

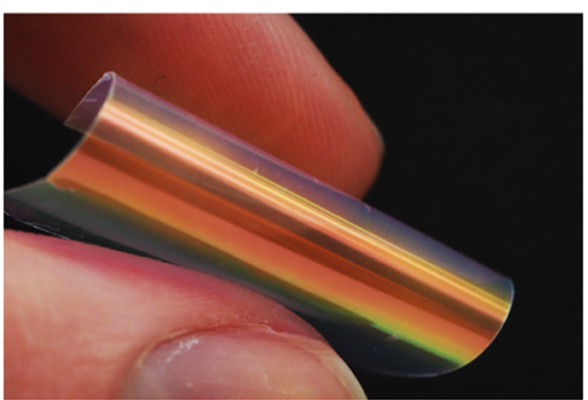

(d)

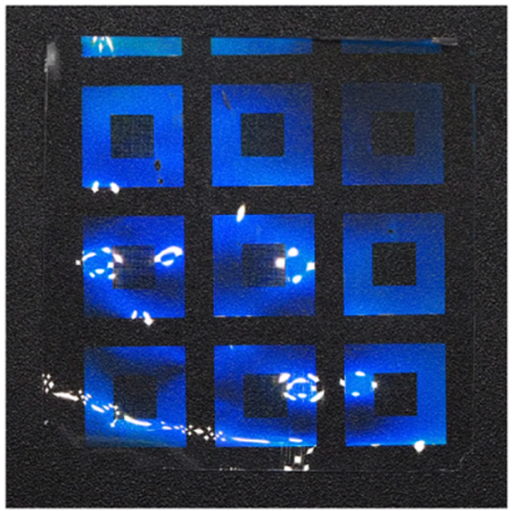

(e)

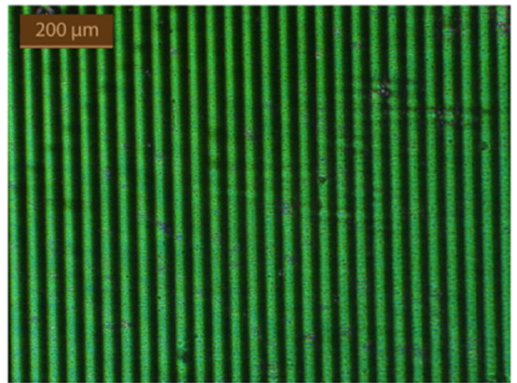

Figure 2. Free-standing chiral nematic oxetane LC foils, dimensions: $3 \times 3 \mathrm{~cm}^{2}$. (a) Photographs of foils prepared with increasing concentration 3 . (b) UV-vis transmission and reflection spectra of mixtures containing 4\% (red line), 5\% (green line), and 5.7\% (blue line) of chiral dopant 3. (c) Prepared foils can easily withstand bending, demonstrating the iridescent angular dependence of a Ch-LC reflecting film. (d) Photograph of lithographically patterned chiral nematic-isotropic film. (e) Micrograph of a patterned film with $20 \mu \mathrm{m}$ features.

coatings, the substrate was polymerized using an Omnicure EXFO2000 UV source at $7 \mathrm{~mW} / \mathrm{cm}^{2}$ through a photomask for 30 s. The sample was then heated to $85{ }^{\circ} \mathrm{C}$ (above the isotropic transition) and polymerized at full intensity $\left(30 \mathrm{~mW} / \mathrm{cm}^{2}\right)$ for $5 \mathrm{~min}$.

\section{RESULTS AND DISCUSSION}

For the fabrication of oxetane-based chiral nematic LC foils and coatings, we designed a nematic oxetane RM mixture that is composed of difunctional oxetane crosslinker $\mathbf{1}$ and monofunctional oxetane 2 (Figure 1a) reported earlier in the literature. To obtain a chiral nematic phase, a chiral dopant is required. Therefore, we designed and synthesized chiral dioxetane 3. This compound is based on an isosorbide core, which was chosen because of the high helical twisting power (HTP) values that are reported for chiral dopants derived from isosorbide. $^{42,43}$ This means that only a small amount of the dopant is required to reflect visible light.

Synthesis of Oxetane-Functionalized Chiral Dopant. First, dioxetane-functionalized chiral dopant 3 was synthesized. The synthesis of 3 is outlined in Scheme 1. Since the oxetane group is known to be labile towards acidic treatments, ${ }^{44}$ we decided to synthesize the molecule from the inside out. First, we attached two benzene rings to the isosorbide core by esterifying isosorbide with 4-hydroxybenzoic acid. This addition of benzene rings should further increase the helical twisting power of the dopant. ${ }^{45-47}$

To do this, the hydroxyl group in 4-hydroxybenzoic acid first needed to be protected to avoid side reactions during the esterification reaction. Therefore, 4-hydroxybenzoic acid was protected with dihydropyran using $p$-toluenesulfonic acid as an acidic catalyst. ${ }^{48}$ This resulted in the formation of tetrahydropyranyl (THP) ether 6 . This compound was then esterified with D-isosorbide to obtain THP-protected diol 2, under mild Steglich conditions using (1-ethyl-3-(3-dimethylaminopropyl)carbodiimide) (EDC) as the coupling agent and 4dimethylamino pyridine (DMAP) as the catalyst. Although some byproducts were formed, 7 could be isolated by silica gel chromatography. Characterization of this molecule by ${ }^{1} \mathrm{H}$ NMR, ${ }^{13} \mathrm{C}$ NMR, and high-resolution mass spectrometry (MALDI-TOF) confirmed the formation of 7. Next, this compound was deprotected using pyridinium $p$-toluenesulfonate (PPTS) in ethanol, giving diol 8, its spectral properties were in accordance with previously reported literature values. ${ }^{49}$ Finally, 8 was esterified under Steglich conditions using EDC and DMAP with readily available oxetane-functionalized carboxylic acid 9 to yield the desired chiral dopant 3 in a moderate yield. Full characterization of the molecule by ${ }^{1} \mathrm{H}$ $\mathrm{NMR},{ }^{13} \mathrm{C} \mathrm{NMR}$, and MALDI-TOF confirmed the structure of 3.

Fabrication of Free-Standing Chiral Nematic Foils. To test the ability of 3 to form chiral nematic phases, we first fabricated free-standing foils in a glass cell. To do so, LC monomer mixtures were prepared containing LC oxetane crosslinker 1, monofunctional LC oxetane 2, chiral dopant 3, and photoinitiator 4 (Figure 1a). The three compositions of these mixtures were chosen such that a blue, green, and red reflective foil was obtained (vide infra). Each mixture contained $75 \%(\mathrm{w} / \mathrm{w})$ of difunctional $(5.7,5$, and $4 \% 3$ in 1) and $25 \%$ of monofunctional (2) monomers. Thermal characterization by polarized optical microscopy (POM) and 
(a)

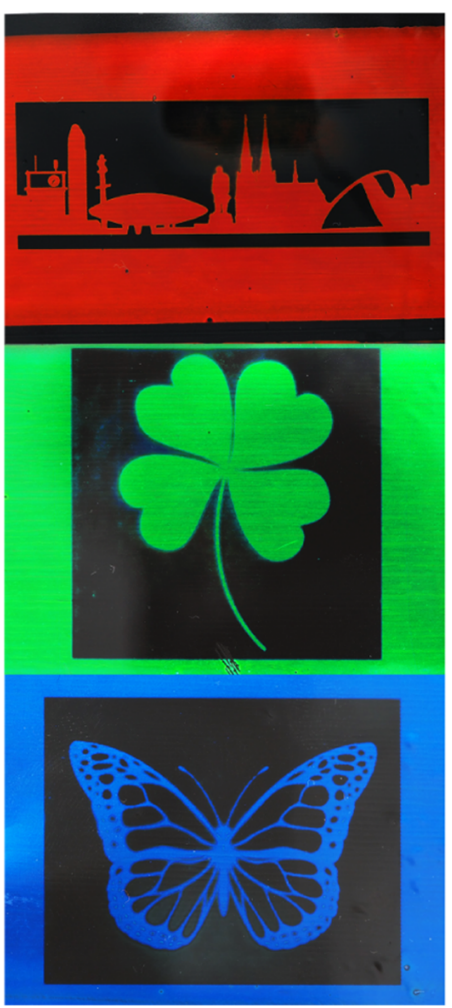

(b)

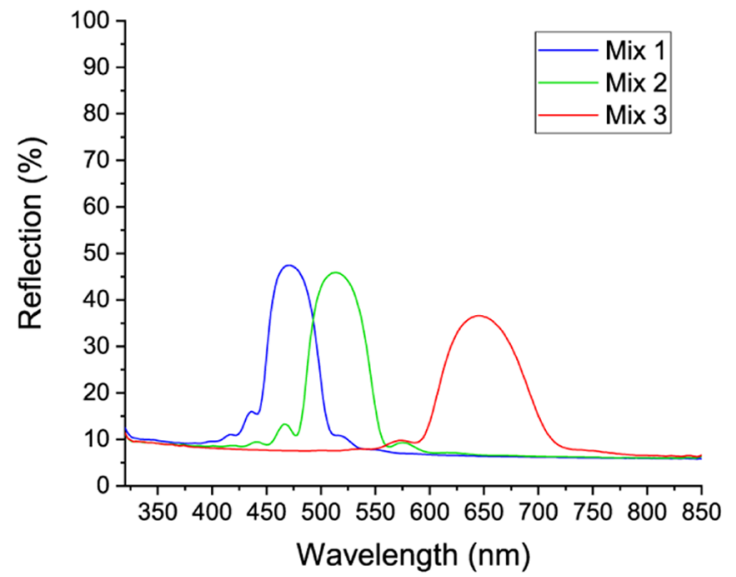

(c)

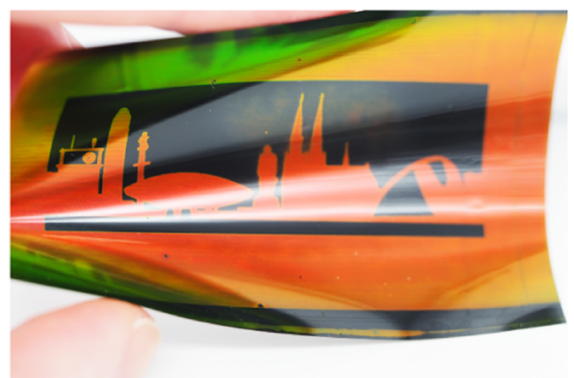

(d)

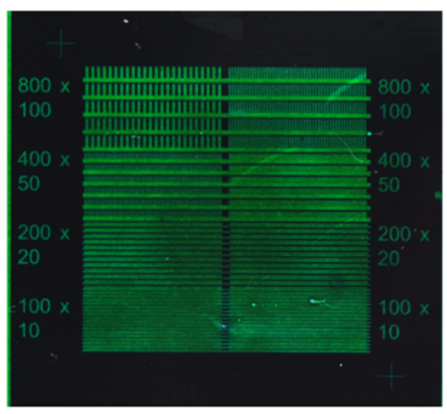

(e)

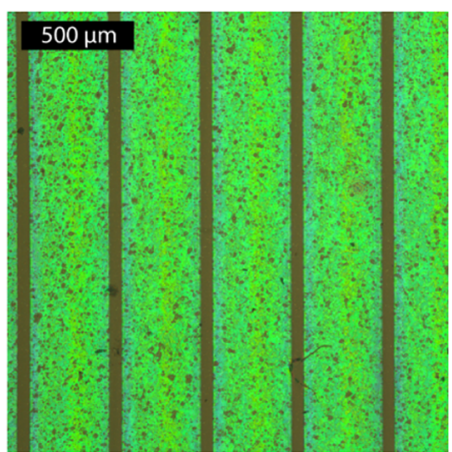

Figure 3. Chiral nematic oxetane LC coatings on a flexible substrate. (a) Photographs of coatings prepared with increasing concentration 3 and lithographically patterned. (b) UV-vis spectra taken from the reflective areas of the samples in (a). (c) Due to the photonic band structure of the coatings, the iridescent color of the red coating in a (a) ranges from initially red to green, depending on the viewing angle. (d) Photograph of lithographically patterned chiral nematic-isotropic coating with highly detailed features. (e) Micrograph of coating shown in (d) with $20 \mu \mathrm{m}$ isotropic features.

differential scanning calorimetry (DSC) showed a chiral nematic to isotropic $\left(\mathrm{N}^{*}-\mathrm{I}\right)$ transition at around $60{ }^{\circ} \mathrm{C}$ (Figure S5). The mixtures did not crystallize on the time scale of the DSC measurement $(>1 \mathrm{~h})$. This indicates that foils that are prepared from this mixture will be stable before photopolymerization for a relatively long time.

Free-standing foils were prepared by sandwiching the monomer mixture between two glass substrates (without alignment layers) in its isotropic phase to ensure homogeneous spreading. The resulting LC cells were then cooled below the $\left(\mathrm{N}^{*}\right.$-I) transition temperature of the monomers. Planar alignment of the LC mixture was achieved by shearing the glass substrates. The mixture was then photopolymerized at 55 ${ }^{\circ} \mathrm{C}$ by subjecting the cell to $7 \mathrm{~mW} / \mathrm{cm}^{2}$ of $365 \mathrm{~nm} \mathrm{UV} \mathrm{light} \mathrm{for}$ $10 \mathrm{~min}$. The resulting polymeric film could very easily be removed from the substrate. FTIR measurements indicated the disappearance of oxetane groups upon polymerization (Figure S6). Thermal analysis of the foils by DSC showed a glass transition between 55 and $62{ }^{\circ} \mathrm{C}$ (Figure S7). Dynamic mechanical thermal analysis (DMTA) of the same foil revealed a room temperature storage modulus of $1.55 \mathrm{GPa}$ (Figure S8), which is typical for highly crosslinked systems. ${ }^{50}$

As mentioned, the amount of $\mathbf{3}$ was varied to tune the color of the foils, ranging from red to blue (Figure $2 \mathrm{a}$ ). We found that adding $5.7 \%(\mathrm{w} / \mathrm{w})$ of 3 results in a blue reflection band, whereas 5.0 and $4.0 \%$ are required for green and red reflection, respectively. This color of the foils is in accordance with selective reflection bands measured by UV-vis spectroscopy (Figure 2b). Mixtures 1 (red), 2 (green), and 3 (blue) show a reflection band that is centered around 660,525 , and $470 \mathrm{~nm}$, respectively. This means that the helical twisting power (HTP) of 3 in the oxetane RM mixtures is around $56 \mu \mathrm{m}^{-1}$ (Figure S9), which is comparable to the HTP of the previously reported acrylate counterpart of $3 .^{46}$ Moreover, both the transmission and reflection spectra show that the foils reflect $50 \%$ of the incident unpolarized light. This is in accordance with the reflection limit of a chiral nematic phase. On the basis of the handedness of the helix, one handedness of circularly polarized light is reflected, whereas the other is transmitted. ${ }^{25}$ Furthermore, the fact that the foils reflect $50 \%$ of incoming light shows that the Ch-LC phase is properly aligned.

Although the free-standing foils obtained consist of an LCN that is highly crosslinked, the resulting foils are still very flexible. As shown in Figure 2c, bending of the foils is easily possible without material failure. By bending the foils, the iridescent angular dependence of the Ch-LC foils can be demonstrated by simultaneously viewing the foil from multiple angles of incidence. Moreover, this bending can be repeated many times without causing visible damage (Figure S10), indicating that the backbone of the formed polyoxetane networks is quite flexible in a bending type loading.

To obtain patterned photonic foils, we used a lithographic $\mathrm{UV}$-curing procedure. This process that is used to create a film with both chiral nematic and isotropic areas is shown in Figure 1c. First, a cell containing an aligned Ch-LC mixture was illuminated through a photomask for $30 \mathrm{~s}$. This fixes the chiral nematic state in the illuminated areas. Next, the photomask was removed and the cell was heated to above the $\mathrm{N}^{*}$-I 
transition temperature of the $\mathrm{CH}-\mathrm{LC}$ mixture $\left(90{ }^{\circ} \mathrm{C}\right)$, which changed the nonilluminated areas to the isotropic state. A flood exposure was then performed for $10 \mathrm{~min}$ to cure the entire film. This procedure resulted in patterned $\mathrm{N}^{*}$-I foils (Figure 2d). The transitions between the chiral nematic and isotropic regions are very sharp (inset, Figure S11). We also show that even $20 \mu \mathrm{m}$ features can be lithographically patterned into the foils (line pattern, Figure 2e), which is smaller than can be seen by the naked eye.

Chiral Nematic Coatings via Flexographic Printing. For flexographic printing, we first developed an ink based on the same oxetane LC mixture used for the preparation of the free-standing foils. This time, surfactant 5 was added to the mixture to facilitate planar alignment of the chiral nematic LCs at the coating-air interface. ${ }^{30} \mathrm{~A}$ solvent compatible with the flexographic printer was used to formulate the oxetane LC ink. To prepare the coatings, the ink was applied against the doctor blade of the printer (Figure 1b). Next, the anilox roll was turned against the doctor blade to spread the ink evenly. The anilox was then pressed against the printing roll to transfer the ink onto the substrate, hence producing an LC coating. Biaxially oriented PET was selected as the substrate, because it is a widely used substrate for industrial coatings. After printing, the solvent was evaporated at an elevated temperature $\left(55^{\circ} \mathrm{C}\right)$, which led to the alignment of the LCs and the appearance of an iridescent reflection. The coatings were then polymerized using a photomask in air, followed by flood polymerization, to obtain the patterns shown in Figure 3a.

The reflection spectra (Figure $3 b$ ) show that for the blue and green coatings, the reflection bands almost reach their $50 \%$ reflection limit. The red spectrum reaches almost $40 \%$ reflection, indicating that the coating thickness is just too thin to obtain a full $50 \%$ reflection band. Furthermore, the spectra show interference peaks surrounding the main reflection peak, indicating the good planar alignment generated by flexographic printing. The angular dependence of the colored appearance of the coatings is clearly visible when looking at the coating under multiple angles of incidence, demonstrating the iridescence of the chiral nematic film (Figure 3c). Furthermore, the coatings turned out to be stable towards various external stimuli, including bending (Figure S12), elevated temperature, and immersion in water (Figure S13).

Finally, we studied the resolution of the patterned coatings by using a photomask with feature sizes changing from 100 to $10 \mu \mathrm{m}$ (Figure $3 \mathrm{~d}$ ). When patterning coatings lithographically, the photomask cannot be placed directly on the coated substrate, as this will fix the photomask to the coating upon polymerization. As a consequence, the photomask must be placed slightly above the coating, potentially leading to a decrease in resolution in the resulting image. Nevertheless, we were still able to produce isotropic lines of $20 \mu \mathrm{m}$ width in a chiral nematic coating (Figure 3e). This resolution is higher than the resolution of a recent high-resolution LCD display, which has a pixel size of about $150 \mu \mathrm{m} .^{51}$ The preservation of such high resolution could be explained by, first, the fact that cationic ring-opening polymerizations are less sensitive to UV light, that is, upon illumination, induction periods have been observed in the oxetane monomer before polymerization occurs. $^{52}$ Therefore, UV light that leaks into the nonilluminated areas does not lead to a substantial amount of crosslinking. ${ }^{37}$ Second, since the cationic ring-opening polymerization of an oxetane is relatively slow compared to, for example, free-radical polymerization of an acrylate, the kinetic chain length is shorter for the oxetane polymerization. This means that the probability for a propagating chain to penetrate the nonilluminated areas is small for the oxetane polymerization.

\section{CONCLUSIONS}

We have shown that extending the molecular toolbox of liquid crystalline oxetanes with a chiral dopant enables the fabrication of oxetane-based photonic materials with excellent processing properties. By incorporating this chiral dopant into a nematic oxetane RM mixture, free-standing Ch-LC foils can be produced by shear-aligning the LCs in a glass cell. These free-standing foils are highly flexible and can be lithographically patterned with a high resolution.

In addition, we have found that the oxetane Ch-LC mixtures are very suitable for fabricating photonic coatings on flexible substrates using flexographic printing. Because this technique is widely used in industry, upscaling of the production process should be relatively straightforward. Additionally, the use of oxetane-based LCs has a major benefit over previously described acrylate systems as no inert atmosphere is required for the photopolymerization of the printed coatings.

Similar to what we have found in Ch-LC free-standing foils, the printed Ch-LC coatings can also be lithographically patterned during photopolymerization. The obtained patterned coatings consist of chiral nematic and isotropic regions with a high resolution. Combined with the simple production method, and the versatility of patterns that can be obtained by using different photomasks, we assert that these patterned photonic materials have potential application in both esthetic coatings as well as anticounterfeit labels. In future work, the production speed could be further increased by implementing the required pattern into the printing roll of the flexographic printer. This way, the desired pattern can be directly printed onto the coating.

\section{ASSOCIATED CONTENT}

\section{S Supporting Information}

The Supporting Information is available free of charge on the ACS Publications website at DOI: 10.1021/acsami.8b21464.

Synthetic details, NMR spectra, analysis of chiral nematic mixtures, thermal analysis of foils, stability of foils and coatings (PDF)

\section{AUTHOR INFORMATION}

\section{Corresponding Author}

*E-mail: a.p.h.j.schenning@tue.nl.

ORCID $\odot$

Davey C. Hoekstra: 0000-0002-4471-588X

Michael G. Debije: 0000-0001-8844-1115

Albert P. H. J. Schenning: 0000-0002-3485-1984

\section{Author Contributions}

This manuscript was written through contributions of all authors. All authors have given approval to the final version of this manuscript.

\section{Funding}

This work was financially supported by the Netherlands Organization for Scientific Research (TOP-PUNT 718.016.003). 


\section{Notes}

The authors declare no competing financial interest.

\section{ACKNOWLEDGMENTS}

The authors thank Audrey Debije-Popson for valuable comments on the manuscript.

\section{REFERENCES}

(1) Potyrailo, R. A.; Ghiradella, H.; Vertiatchikh, A.; Dovidenko, K.; Cournoyer, J. R.; Olson, E. Morpho Butterfly Wing Scales Demonstrate Highly Selective Vapour Response. Nat. Photonics 2007, 1, 123-128.

(2) Vignolini, S.; Moyroud, E.; Hingant, T.; Banks, H.; Rudall, P. J.; Steiner, U.; Glover, B. J. The Flower of Hibiscus trionum Is Both Visibly and Measurably Iridescent. New Phytol. 2015, 205, 97-101.

(3) Liu, F.; Dong, B. Q.; Liu, X. H.; Zheng, Y. M.; Zi, J. Structural Color Change in Longhorn Beetles Tmesisternus isabellae. Opt. Express 2009, 17, 16183.

(4) Sun, J.; Bhushan, B.; Tong, J. Structural Coloration in Nature. RSC Adv. 2013, 3, 14862-14889.

(5) Shen, H.; Wang, Z.; Wu, Y.; Yang, B. One-Dimensional Photonic Crystals: Fabrication, Responsiveness and Emerging Applications in 3D Construction. RSC Adv. 2016, 6, 4505-4520.

(6) Mulder, D. J.; Schenning, A. P. H. J.; Bastiaansen, C. W. M. Chiral-Nematic Liquid Crystals as One Dimensional Photonic Materials in Optical Sensors. J. Mater. Chem. C 2014, 2, 6695-6705.

(7) Moirangthem, M.; Arts, R.; Merkx, M.; Schenning, A. P. H. J. An Optical Sensor Based on a Photonic Polymer Film to Detect Calcium in Serum. Adv. Funct. Mater. 2016, 26, 1154-1160.

(8) Lova, P.; Bastianini, C.; Giusto, P.; Patrini, M.; Rizzo, P.; Guerra, G.; Iodice, M.; Soci, C.; Comoretto, D. Label-Free Vapor Selectivity in Poly(p-Phenylene Oxide) Photonic Crystal Sensors. ACS Appl. Mater. Interfaces 2016, 8, 31941-31950.

(9) Khan, M. K.; Bsoul, A.; Walus, K.; Hamad, W. Y.; Maclachlan, M. J. Photonic Patterns Printed in Chiral Nematic Mesoporous Resins. Angew. Chem., Int. Ed. 2015, 54, 4304-4308.

(10) Nam, H.; Song, K.; Ha, D.; Kim, T. Inkjet Printing Based Mono-Layered Photonic Crystal Patterning for Anti-Counterfeiting Structural Colors. Sci. Rep. 2016, 6, No. 30855.

(11) Moirangthem, M.; Schenning, A. P. H. J. Full Color Camouflage in a Printable Photonic Blue-Colored Polymer. ACS Appl. Mater. Interfaces 2018, 10, 4168-4172.

(12) Fang, Y.; Ni, Y.; Leo, S. Y.; Wang, B.; Basile, V.; Taylor, C.; Jiang, P. Direct Writing of Three-Dimensional Macroporous Photonic Crystals on Pressure-Responsive Shape Memory Polymers. ACS Appl. Mater. Interfaces 2015, 7, 23650-23659.

(13) Ge, J.; Goebl, J.; He, L.; Lu, Z.; Yin, Y. Rewritable Photonic Paper with Hygroscopic Salt Solution as Ink. Adv. Mater. 2009, 21, 4259-4264.

(14) Wan, H.; Li, X.; Zhang, L.; Li, X.; Liu, P.; Jiang, Z.; Yu, Z. Z. Rapidly Responsive and Flexible Chiral Nematic Cellulose Nanocrystal Composites as Multifunctional Rewritable Photonic Papers with Eco-Friendly Inks. ACS Appl. Mater. Interfaces 2018, 10, 59185925.

(15) Moirangthem, M.; Scheers, A. F.; Schenning, A. P. H. J. A Full Color Photonic Polymer, Rewritable with a Liquid Crystal Ink. Chem. Commun. 2018, 54, 4425-4428.

(16) Nakamura, C.; Manabe, K.; Tenjimbayashi, M.; Tokura, Y.; Kyung, K. H.; Shiratori, S. Heat-Shielding and Self-Cleaning Smart Windows: Near-Infrared Reflective Photonic Crystals with SelfHealing Omniphobicity via Layer-by-Layer Self-Assembly. ACS Appl. Mater. Interfaces 2018, 10, 22731-22738.

(17) Zhang, L.; Wang, M.; Wang, L.; Yang, D. K.; Yu, H.; Yang, H. Polymeric Infrared Reflective Thin Films with Ultra-Broad Bandwidth. Liq. Cryst. 2016, 43, 750-757.

(18) Khandelwal, H.; Schenning, A. P. H. J.; Debije, M. G. Infrared Regulating Smart Window Based on Organic Materials. Adv. Energy Mater. 2017, 7, No. 1602209.
(19) Liu, D.; Broer, D. J. Liquid Crystal Polymer Networks: Preparation, Properties, and Applications of Films with Patterned Molecular Alignment. Langmuir 2014, 30, 13499-13509.

(20) Bai, L.; Xie, Z.; Wang, W.; Yuan, C.; Zhao, Y.; Mu, Z.; Zhong, Q.; Gu, Z. Bio-Inspired Vapor-Responsive Colloidal Photonic Crystal Patterns by Inkjet Printing. ACS Nano 2014, 8, 11094-11100.

(21) van der Zande, B. M. I.; Steenbakkers, J.; Lub, J.; Leewis, C. M.; Broer, D. J. Mass Transport Phenomena during Lithographic Polymerization of Nematic Monomers Monitored with Interferometry. J. Appl. Phys. 2005, 97, No. 123519.

(22) Zhang, P.; Kragt, A. J. J.; Schenning, A. P. H. J.; De Haan, L. T.; Zhou, G. An Easily Coatable Temperature Responsive Cholesteric Liquid Crystal Oligomer for Making Structural Colour Patterns. J. Mater. Chem. C 2018, 6, 7184-7187.

(23) Burgess, I. B.; Mishchenko, L.; Hatton, B. D.; Kolle, M.; Lončar, M.; Aizenberg, J. Encoding Complex Wettability Patterns in Chemically Functionalized 3D Photonic Crystals. J. Am. Chem. Soc. 2011, 133, 12430-12432.

(24) Lee, H. S.; Kim, J. H.; Lee, J. S.; Sim, J. Y.; Seo, J. Y.; Oh, Y. K.; Yang, S. M.; Kim, S. H. Magnetoresponsive Discoidal Photonic Crystals toward Active Color Pigments. Adv. Mater. 2014, 26, 58015807.

(25) Mitov, M. Cholesteric Liquid Crystals with a Broad Light Reflection Band. Adv. Mater. 2012, 24, 6260-6276.

(26) Fan, J.; Li, Y.; Bisoyi, H. K.; Zola, R. S.; Yang, D. K.; Bunning, T. J.; Weitz, D. A.; Li, Q. Light-Directing Omnidirectional Circularly Polarized Reflection from Liquid-Crystal Droplets. Angew. Chem., Int. Ed. 2015, 54, 2160-2164.

(27) Bisoyi, H. K.; Li, Q. Light-Driven Liquid Crystalline Materials: From Photo-Induced Phase Transitions and Property Modulations to Applications. Chem. Rev. 2016, 116, 15089-15166.

(28) Bisoyi, H. K.; Li, Q. Light-Directed Dynamic Chirality Inversion in Functional Self-Organized Helical Superstructures. Angew. Chem., Int. Ed. 2016, 55, 2994-3010.

(29) van Heeswijk, E. P. A.; Kloos, J. J. H.; de Heer, J.; Hoeks, T.; Grossiord, N.; Schenning, A. P. H. J. Well-Adhering, Easily Producible Photonic Reflective Coatings for Plastic Substrates. ACS Appl. Mater. Interfaces 2018, 10, 30008-30013.

(30) Kragt, A. J. J.; Broer, D. J.; Schenning, A. P. H. J. Easily Processable and Programmable Responsive Semi-Interpenetrating Liquid Crystalline Polymer Network Coatings with Changing Reflectivities and Surface Topographies. Adv. Funct. Mater. 2018, 28, No. 1704756

(31) Zhang, W.; Kragt, S.; Schenning, A. P. H. J.; De Haan, L. T.; Zhou, G. Easily Processable Temperature-Responsive InfraredReflective Polymer Coatings. ACS Omega 2017, 2, 3475-3482.

(32) Kim, D.-Y.; Lee, K. M.; White, T. J.; Jeong, K.-U. Cholesteric Liquid Crystal Paints: In Situ Photopolymerization of Helicoidally Stacked Multilayer Nanostructures for Flexible Broadband Mirrors. NPG Asia Mater. 2018, 1061-1068.

(33) Li, Y.; Liu, Y. J.; Dai, H. T.; Zhang, X. H.; Luo, D.; Sun, X. W. Flexible Cholesteric Films with Super-Reflectivity and High Stability Based on a Multi-Layer Helical Structure. J. Mater. Chem. C 2017, 5, 10828-10833.

(34) White, T. J.; Broer, D. J. Programmable and Adaptive Mechanics with Liquid Crystal Polymer Networks and Elastomers. Nat. Mater. 2015, 14, 1087-1098.

(35) Broer, D. J.; Boven, J.; Mol, G. N.; Challa, G. In-Situ Photopolymerization of Oriented Liquid-Crystalline Acrylates, 3. Die Makromol. Chem. 1989, 190, 2255-2268.

(36) Studer, K.; Decker, C.; Beck, E.; Schwalm, R. Overcoming Oxygen Inhibition in UV-Curing of Acrylate Coatings by Carbon Dioxide Inerting, Part I. Prog. Org. Coat. 2003, 48, 92-100.

(37) Van Der Zande, B. M. I.; Roosendaal, S. J.; Doornkamp, C.; Steenbakkers, J.; Lub, J. Synthesis, Properties, and Photopolymerization of Liquid-Crystalline Oxetanes: Application in Transflective Liquid-Crystal Displays. Adv. Funct. Mater. 2006, 16, 791-798. 
(38) Hikmet, R. A. M.; Lub, J.; Higgins, J. A. Anisotropic Networks Obtained by in Situ Cationic Polymerization of Liquid-Crystalline Divinyl Ethers. Polymer 1993, 34, 1736-1740.

(39) Broer, D. J.; Lub, J.; Mol, G. N. Synthesis and Photopolymerization of a Liquid-Crystalline Diepoxide. Macromolecules 1993, 26, 1244-1247.

(40) Lub, J.; Recaj, V.; Puig, L.; Forcén, P.; Luengo, C. Synthesis, Properties and Photopolymerization of Liquid Crystalline Dioxetanes. Liq. Cryst. 2004, 31, 1627-1637.

(41) Jahromi, S.; Lub, J.; Mol, G. N. Synthesis and Photoinitiated Polymerization of Liquid Crystalline Diepoxides. Polymer 1994, 35, 622-629.

(42) Goodby, J. W.; Slaney, A. J.; Booth, C. J.; Nishiyama, I.; Vuijk, J. D.; Styring, P.; Toyne, K. J. Chirality and Frustration in Ordered Fluids. Mol. Cryst. Liq. Cryst. Sci. Technol., Sect. A 1994, 243, 231-298.

(43) Meyer, F.; Ishida, H.; Schuhmacher, P. (BASF AG, Germany) Chiral compound used as polymerizable, high-twisting-power dopant for the production of cholesteric networks. Ger. Offen. DE19843724A1, April 15, 1999.

(44) Wang, Z.; Chen, Z.; Sun, J. Catalytic Asymmetric Nucleophilic Openings of 3-Substituted Oxetanes. Org. Biomol. Chem. 2014, 12, $6028-6032$.

(45) Lub, J.; Nijssen, W. P. M.; Wegh, R. T.; De Francisco, I.; Ezquerro, M. P.; Malo, B. Photoisomerizable Chiral Compounds Derived from Isosorbide and Cinnamic Acid. Liq. Cryst. 2005, 32, 1031-1044.

(46) Lub, J.; Nijssen, W. P. M.; Wegh, R. T.; Vogels, J. P. A.; Ferrer, A. Synthesis and Properties of Photoisomerizable Derivatives of Isosorbide and Their Use in Cholesteric Filters. Adv. Funct. Mater. 2005, 15, 1961-1972.

(47) Shin, S.; Park, M.; Ku Cho, J.; Char, J.; Gong, M.; Jeong, K. U. Tuning Helical Twisting Power of Isosorbide-Based Chiral Dopants by Chemical Modifications. Mol. Cryst. Liq. Cryst. 2011, 534, 19-31. (48) Hikmet, R. A. M.; Lub, J.; Tol, A. J. W. Effect of the Orientation of the Ester Bonds on the Properties of Three Isomeric Liquid Crystal Diacrylates before and after Polymerization. Macromolecules 1995, 28, 3313-3327.

(49) Goldfinger, M. B.; Rodriguez-Parada, J. M.; Silverman, L. Liquid Crystal Compositions, Polymer Networks Derived Therefrom and Process For Making the Same. U.S. Patent 2007228326, 2007.

(50) Hikmet, R. A. M.; Broer, D. J. Dynamic Mechanical Properties of Anisotropic Networks Formed by Liquid Crystalline Acrylates. Polymer 1991, 32, 1627-1632.

(51) HP Development Company. HP 4K UHD Displays: Explaining Ultra High Definition (UHD), and Why It Matters [White Paper]. http://h20195.www2.hp.com/V2/GetPDF.aspx/4AA5-7763ENW (accessed Jan 16, 2019).

(52) Bulut, U.; Crivello, J. V. Reactivity of Oxetane Monomers in Photoinitiated Cationic Polymerization. J. Polym. Sci., Part A: Polym. Chem. 2005, 43, 3205-3220. 